\title{
À força de padecer: considerações sobre a dor como experiência ontológica
}

Irene Borges-Duarte ${ }^{1}$

Universidade de Évora

E-mail: ibd@uevora.pt

Para Zeljko Loparic com admiração e afecto, procurando os sinais de um novo paradigma.

Resumo: A dor e o sofrimento têm tido, ao longo da história, um lugar especial no âmbito da filosofia prática. Do ponto de vista do cuidado de si, são aquilo que a moral grega procura evitar, com a racionalidade da conduta orientada para a eudaimonia. Do ponto de vista cristão, têm um papel redentor no caminho para vencer o terrenal. Em ambos os casos, são marca e sintoma do que hoje chamamos condição antropológica: sofrer é ser vulnerável à dor e à morte, quer própria quer alheia. Nesse sentido, a vulnerabilidade impregna a existência do ser humano e é susceptível de abordagens positivas e epistemológicas. No entanto, de um ponto de vista fenomenológico, é a experiência da dor, nos seus abismos e ápices, que revela esse modo de ser em que o ente humano se encontra com a sua pele ontológica: com o limite do seu ser, em que soma e psyche se não distinguem. É essa experiência ontológica do limite que vou procurar abordar, num contexto em que a fenomenologia e a psicanálise se tocam, e se diferenciam aspectos existenciais, culturais e cognitivos.

Palavras-chave: Dor ; vulnerabilidade; experiência; pathos.

Abstract: By force of suffering. Considerations about pain as an ontological experience. Pain and suffering have, throughout history, had a special place within practical philosophy. From the point of view of self-care, they are what Greek morals seek to avoid, with the rationality of eudaimoniaoriented conduct. From the Christian point of view, they have a redemptive role on the path to overcoming the earthly. In both cases, they are a mark and symptom of what we today call an

\footnotetext{
${ }^{1}$ Professora associada na Universidade de Évora e investigadora no Praxis/UÉ, onde oordena a linha de investigação em Fenomenologia. Foi docente na Universidade Complutense de Madrid (1992/1996), onde se doutorou, em 1994, com uma tese em Filosofia sobre Heidegger e Kant. Formação nas universidades de Lisboa, Madrid (Complutense), Mainz e Freiburg i. Breisgau. Actividade investigadora no horizonte de uma Ontologia hermenêutica e fenomenológica, com especial atenção à questão e prática da tradução (projecto «Heidegger em Português»), à Filosofia da Técnica, à Psicanálise e à Análise existencial de raiz heideggeriana. Foi directora do Curso de Doutoramento em Filosofia na UÉ e presidente da direcção da Associação Portuguesa de Filosofia Fenomenológica (AFFEN). Integra actualmente a direcção da Sociedade Iberoamericana de Estudos Heideggerianos (SIEH).
} 
anthropological condition: to suffer is to be vulnerable to pain and death, whether one's own or of others. In this sense, vulnerability permeates the existence of the human being and is susceptible to positive and epistemological approaches. However, from a phenomenological point of view, it is the experience of pain, in its abyss and apexes, that reveals this way of being in which the human being meets his ontological skin, the limits of his being, in which soma and psyche are not distinguished. It is this ontological experience of the limit that I will seek to address, in a context in which phenomenology and psychoanalysis touch each other and where existential, cultural and cognitive aspects are to be differenciated.

Keywords: Pain; Vulnerability; Experience; Pathos.

A acentuada atenção que tem vindo a ser prestada, ultimamente, aos elementos páticos da experiência, no seio do movimento fenomenológico - apesar deste ter nascido mais centrado nos elementos noético-noemáticos claramente intencionais -, tem permitido uma aproximação cada vez mais decidida a uma problemática tão marginal como a da dor e do sofrimento. Esta orientação fenomenológica surge, na filosofia, da progressiva importância da abordagem existencial, com base em Jaspers e Heidegger, bem como no carácter central que a afectividade e os afectos alcançaram nas perspectivas de Max Scheler e do próprio Heidegger, que procuraram, nos modos emotivos do encontro com o que constitui o mundo da vida, a via regia de descrever o ser à maneira humana. Em qualquer caso, pois, a questão da dor aparece no contexto de uma fenomenologia da vida ou da existência humana, e é dificilmente desligável de uma concepção antropológica.

Tendo em consideração esta situação hermenêutica, é minha intenção, aqui, procurar libertar no conceito a experiência que está na sua origem e tentar responder a uma questão simples: de que maneira pode a experiência da dor abrir um "aí" para o acolher com cuidado do que vem a ser, seja o novo, que antes não era, na sua chegada, seja o que já estava a ser, mas encoberto e, talvez por isso mesmo, avassalador. Formulada desta maneira, a pergunta destaca-se de um fundo heideggeriano, muito embora o próprio filósofo a não tenha formulado inicialmente. Não aparece em Ser e tempo, e as referências prévias às moléstias, que transem a vida quotidiana, estão muito aquém da intensidade que, nos anos 1940, o próprio Heidegger chegará a atribuir à questão da dor, enquanto acuidade de um saber (de experiência) propiciador de um possível início, enquanto Ereignis.

Mas o que me proponho aqui realizar não é um estudo do pensador Heidegger. Apenas procuro nele, como também em Freud, Winnicott e Jünger, entre outros, algum apoio para explicitar o que, no meu modo de ver, a dor significa de um ponto de vista ontológico. Quero 
com isso dizer que não me interessa apenas usar a dor como instrumento conceptual para caracterizar a vulnerabilidade da condição humana - o que, decerto, também fará parte deste percurso -, mas procurar, na dor, o carácter distintivo do ser à maneira humana: a experiência do limite, que exige um tomar em propriedade e uma aceitação da finitude. A repercussão desta experiência tem necessariamente uma extensão "terapêutica", quer do ponto de vista médico ou psicológico, quer, sobretudo, na decisão de uma forma de vida e de relação consigo mesmo e com os outros.

Vou partir, muito brevemente, das primeiras considerações da dor, no contexto da moral antiga e cristã, para encontrar nelas o registo da profundidade do fenómeno encontrado e da sua interpretação "moral". Saltarei, então, ao que tentarei mostrar nos três contextos em que se desenvolve a certeza da dor: a dor dita "física", a "psíquica" e a propriamente "moral", que marcam a nossa vulnerabilidade. Mas procurarei abdicar dessas diferenças, pois a acuidade da dor as anula, quer na sua incorporação no quotidiano, no caso do que chamamos dor crónica, quer no da absoluta ruptura com tudo, na dor aguda. É com base nesta característica fundamental, que é a da intensidade e não a da localização da dor, que tentarei defender o carácter transcendental ou ontológico desta experiência.

\section{1. À força de padecer...}

No longo poema "La nuit d' Octobre" (1837), um diálogo do poeta com a sua musa inspiradora acerca de uma paixão destrutiva, Alfred de Musset, um dos cumes do romantismo francês, narra um trajecto que, da dor do amante traído, finalmente, conduz a uma libertação para a vida e para o amor verdadeiro, capazes de voltar a inaugurar um ciclo de criatividade poética. E é a musa que diz ao poeta:

\footnotetext{
O homem é um aprendiz. A dor é seu mestre.

E ninguém se conhece, enquanto não sofreu.

É uma lei dura mas suprema, velha como o mundo e a fatalidade,

que precisamos receber da desgraça o baptismo,

e que esse é o triste preço a que tudo deve ser comprado ${ }^{2}$
}

\footnotetext{
${ }^{2}$ Veja-se "La Nuit d'Octobre" em Musset (2013): "L'homme est un apprenti, la douleur est son maître,/ Et nul ne se connaît tant qu'il n'a pas souffert. / C'est une dure loi, mais une loi suprême, /Vieille comme le monde et la fatalité, / Qu'il nous faut du malheur recevoir le baptême.”
} 
Dor, sofrimento, desgraça são, nesta abordagem poética, lei e fatalidade, são o preço a pagar por aprender a ser humano. Sempre assim foi. É a sua condição e norma suprema: ser aprendiz é aceitar o baptismo da dor. Musset resume, assim, poeticamente, séculos de pensamento: à força de padecer, aprende-se a viver e a até a amar a vida. Esta só tem sabor, se primeiro se fez a experiência dolorosa da perda, que revela o valor do que, só então, se reconhece e se toma autenticamente como próprio. De forma indistinta, a experiência da dor é o patamar da felicidade possível: o para além de, o vencer da miséria e da pena, o saber gozar do que vem ao nosso encontro. Mas o poema é romântico. Que outra coisa poderia narrar de mais penoso e acutilante que o "mal de amor"? Não é, pois, tão indistinto: fala de uma dor "da alma", de um sentimento ou plexo de sentimentos (raiva, orgulho, ódio, impiedade, horror), que se desprendem do amor ferido. A dor é, neste caso, metáfora da complexidade do sofrimento, no seu desdobrar-se temporal. Mas se, no poema, esse é o tempo que aparta o poeta da poesia e da vida, que o afunda em lágrimas e desespero, incapaz de palavra, também é esse o tempo que o faz dar valor à beleza, que paradoxalmente acompanha a memória, e que lhe permite compreender as palavras dos grandes poetas e as obras dos grandes artistas, e perceber como falta a alegria estrondosa patente na natureza. A falta alerta para a plenitude, reclama ser narrada, invoca a musa. Ora, a dor que se conta já não é dor, surge domesticada na palavra, que a amacia. Revela, por um lado, o processo hermenêtico que a transforma em sofrimento. E é, por outro lado, o começo da cura, que, neste caso, é o poema - o diálogo com outro que escuta, acompanha, compreende e responde. A invocação da "Noite de Outubro" de Alfred de Musset percorre este caminho, abrindo uma via de abordagem da primeira questão que aqui nos interessa: o sentido escatológico do padecer, quer no âmbito psicológico, quer moral.

No mundo cristão, a experiência do sofrimento constitui a via crucis que conduz da tentação à redenção, da provação à libertação. Está ligada ao vencer da carne, embora não se reduza à dor física, antes implicando a miséria moral que requer dissolução espiritual, elevação do terreno. A dor é espelho do conglomerado indistinto do mal, que tem origem na doença, na penúria, no desejo, que junta o diabólico com o social, e o físico ou corpóreo com o psíquico e cultural num convolutum conceptualmente inconsistente. Mais que conceito, $a$ dor é uma metáfora do mal, é o que nos transporta para o maldito (maledictus). ${ }^{3}$

\footnotetext{
${ }^{3}$ É, neste sentido, sintomática a análise do fenomenólogo espanhol Miguel García-Baró, que num belo texto sobre o sentido da dor, em que contrasta as concepções grega e cristã, afirma que, nesta última, "a dor é a experiência do mal na sua maldade" (García-Baró, 2012, p. 29). Num texto recentemente publicado, Heidegger Revista Natureza Humana, São Paulo, v.21, n.2, pp.112-129, 2019 
No mundo clássico greco-latino, era, em contrapartida, muito racionalmente, aquilo que havia a evitar, o sintoma da má-vida e da má-sorte, da prática quotidiana desarmónica, imprudente, desequilibrada ou do funesto destino, alheio à própria vontade. Não quis Prometeu que o seu gesto generoso tivesse que pagar o preço da cólera de Zeus, mas foi sua a dor desgarradora infligida pela águia divina. Na maior parte das vezes, porém, são os mortais eles mesmos que, por incúria ou excesso, se inflingem a si próprios os mais diversos modos de sofrimento. A dor é, nesse caso, resultado e sintoma do fracasso da epiméleia heautó, que todos os humanos se devem a si mesmos. Por falta de conhecimento de si, por excesso de desejo, por imaturidade ou desequilíbrio de forças.

Em qualquer destas abordagens, não é, contudo, a dor que centra a atenção do filósofo, mas o seu significado escatológico, moral ou estratégico, na compreensão global da vida humana. $\mathrm{O}$ que, decerto, não é pouco, pois regista a sua relevância essencial para a realização plena da humanidade dos seres humanos. Indica interpretativamente que faz parte destes sentir dor e procurar vencê-la ou incorporá-la no seu tempo vital, sem deixar de criar possibilidades, cuidando de si e dos outros, num mundo comum. Mas não há, nestas abordagens, hermeneuticamente densas de sedimentações culturais, uma fenomenologia da dor ela mesma, não há um deixar que ela se mostre no que ela é.

\section{Para uma fenomenologia da dor}

Que é a dor? Algo que sentimos. Um sentir, mais que um "sentimento": podemos referir-nos ao sentido, isto é, ao que foi sentido, mas em si mesma a dor é sempre in actu, só é dor no acto de senti-la, pelo que falar dela como sentimento é já ultrapassá-la conceptualmente, reduzi-la a uma modalidade de percepção sensível da própria capacidade de a sentir. Do amor, da alegria, do medo, por exemplo, podemos dizer que são "sentimentos", pois continuam a sê-lo na memória e no pensamento, perdurando na nossa atitude vital. A dor, em contrapartida, como o prazer e, talvez, como a vergonha, são tão fugazes quanto um relâmpago, que ilumina a noite, e o que deles nos fica na memória, no pensamento e na atitude vital é a repercussão - a luminosidade - desse instante no tempo da nossa vida, no

aventura uma parecença do fenómeno da dor dizendo que "é o adverso que oprime o ser humano, em diferentes graus e níveis, que vão do desagradável até ao maléfico" (Heidegger, 2017/2018, p. 31). Mas trata-se apenas do que a dor "parece ser" (der Anschein des Schmerzes), numa abordagem metafísica, como vivência no contexto do sentimento, corporal e anímico. Na sequência desse breve texto, procurando superar essa abordagem limitativa, Heidegger (2017/2018, p. 35) atribuir-lhe-á o carácter essencial de ser um "sinal" do Ereignis, como adiante veremos.

Revista Natureza Humana, São Paulo, v.21, n.2, pp.112-129, 2019 
nosso viver quotidiano. A dor, como o prazer, talvez como a vergonha, não é o que perduranão poderíamos suportá-la -, mas o que esse instante fez de nós, o que nos fez perceber: algo em cada um de nós, mas não encerrado em nós (num corpo ou numa psique), afectando o todo apercebido.

É certo, claro, que há dores agudas e dores crónicas. O corpo conhece-as bem: o longo cansaço da dor reumática, que se estende e rouba energia vital, é bem diferente do abrir-se da carne num ferimento ou no súbito quebrar-se de uma perna. A experiência psíquica não é, fundamentalmente, diferente destas: a dor do amante na noite de outubro em que percebe a traição da amada, não dói de modo diferente da ferida de guerra, nem o desespero se sofre sem o esgotamento aniquilador do prolongar-se do instante desgarrador, que não passa. $\mathrm{O}$ tempo da carne e o tempo da alma não se separam nunca: aliam-se na unidade do existir. E a existência é, já de sempre, o estar-a-ser no mundo: ex-posição ao que pode chegar-nos na dor - a flecha real ou a do destino, o vírus da gripe ou o da informática. Não chamamos dor, pois, à fisiologia ou à psicologia do sofrimento, aos centros neuronais em que se regista ou às emoções que a expressam e acompanham, mas à sua chegada avassaladora, ao seu apanharnos de surpresa, ao seu arrasar-nos, interrompendo a nossa vida, nem que seja por uma milésima de segundo. $\mathrm{O}$ instante - esse - não se mede em segundos... A dor é uma forma do tempo irromper, uma forma de ficar retido no instante e não passar.

Esta característica revela-se sempre de forma singular, é sempre como se fosse pela primeira vez. Pode ser mais forte, ou menos forte, claramente localizada ou difusa, repercutindo sem acuidade... mas é sempre sentida como um corte na continuidade do viver, como um golpe e uma fenda que se abre na muralha das nossas rotinas quotidianas, como algo estranho, inassumível. Nela experimentamos sempre um começo, entrevemos um fim - sem, contudo, disso termos consciência, conhecimento propriamente dito. Com razão, diz Heidegger que a dor é o rasgo (Riss) e traço em que se deixa ver a apropriação e desapropriação (Ereignis/Enteignis) do $\operatorname{ser}^{4}$ no seu aí humano, em que se faz e desfaz a experiência culminante e abissal do estar a ser na sua finitude (v. Heidegger, 2009, p. 194). No entanto, a clarividência desse acontecimento oculta-se no próprio processo de sofrê-lo ou padecê-lo: se se liberta na angústia, encobre-se paradoxalmente no espaço-tempo hermenêutico do sofrimento. Não é, por isso, de estranhar a dificuldade em definir o

\footnotetext{
${ }^{4}$ Em ausência de um estudo sistemático sobre a dor em Heidegger, que não é objecto do presente trabalho, tomem-se estas breves referências como indicação de um possível caminho para essa tematização: Heidegger, 2013, pp. 796 e 800; e 2009, p. 236. 
fenómeno da dor, de um ponto de vista cognitivo, isto é, naquilo que ela dá a conhecer. Para poder lá chegar, partamos, então, de dois exemplos.

\section{A dor física}

O caso mais imediato e comprovável de que podemos partir é a experiência corporal do doer-me físico. Desde a mais terna infância experimentamos esse componente vital que é ter um “dói-dói”. Somos preparados para evitar essa eventualidade corriqueira, mas também para a aguentar e ultrapassar. Essa vivência elementar e habitual da dor faz parte da aprendizagem do cuidado de si e também dos outros, na atenção ao intramundano, no domínio do movimento corporal e na expressão da agressividade. A dor, como o prazer, funciona como um alerta pontual, em que se concretiza a capacidade de desenvolvimento e maturação do bebé e da criança. Inicialmente sem sítio, só pouco a pouco poderá vir a ser ligado a uma localização: o bebé não sabe onde lhe dói, apenas sente essa novidade que é a dor. E isso basta-lhe para aprender o que ela é: não é um objecto (ainda não há objectos!), mas sim sinal do desagradável, algo a rejeitar, a expulsar do seu conforto. O bebé também não tem sentimento de si - tal como não há “objectos”, também ainda não há um self-mas apenas um estar indefinido, vital e sensível ao estar-bem ou não-estar. A dor não tem repercussão interior, mas apenas exterior: é o que se traduz em gritos, em choro. Não só até que passe a dor grita ou chora o bebé: a repercussão do que sentiu manifesta-se no tempo do gritar e do chorar. De cada vez, é como se fosse a primeira vez: estentóreo e tenaz é o expulsar do que faz mal. A memória só retém a intensidade do novo no tempo de um dizer, que ainda não tem palavra.

A criança, porém, vai adquirindo, aprendendo e exercendo a capacidade de falar, de reter na memória, de prever e evitar algumas dores. Já situa a dor no seu espaço corporal, objectiva-a, dá-lhe nome: dói-me aqui, tenho um “dói-dói”. Já sabe. Mas ainda chora, ainda berra. Ainda é como da primeira vez. Embora também saiba que, desse modo, chama para si a atenção dos adultos para que venham cuidar dela. E também é uma dor se isso, que ela espera, não acontece: uma dor de outra ordem, mas não menos intensa. No entanto, pouco a pouco, vai-se esta apagando: com a crescente autonomia, vai sendo menos premente a necessária atenção do outro e mais importante a própria acção e o desenvolvimento da objectivização, que se sobrepõe ao sentimento. A dor ganha localização e nome: é dor de dentes, ou dor de cabeça, ou dor de barriga. Só o conceito permite sobrepor-se ao aperceber-se inicial da dor. 
Contudo, o poder dessa experiência inicial não é esquecido e volta a ser efectivo uma e outra vez, ao longo da vida. Estamos sempre à mercê desse poder desgarrador. Às vezes, é tão intenso, que tudo o resto se interrompe. Mas aqui já não é só fisicamente, no corpo, que a dor é sentida, mas na totalidade do estar a ser ou existência. É um fenómeno total.

\title{
4. O trauma da dor
}

Freud, ainda no começo do seu caminho de investigação do padecimento psíquico, soube distinguir muito bem aquilo que era fisiológico do que era psicológico: a reacção física e o trauma psíquico. Ainda em Viena, como assistente de Meynert, ou já em Paris, aprendendo com Charcot, a sua experiência da localização da dor e da perturbação neurótica que a excede é determinante do seu futuro como fundador do que chamou Psicanálise. Nem todos os padecimentos psicológicos são traumáticos, mas a noção de trauma psíquico acrescenta algo importante àquilo que é o conceito elementar de dor, tal como o temos estado a considerar. $\mathrm{Na}$ "Comunicação preliminar" ao texto "Acerca do mecanismo psíquico dos fenómenos histéricos” (1893), que publicou com Breuer, podemos ler:

\begin{abstract}
Nas neuroses traumáticas, a causa eficiente da doença não é a lesão corporal insignificante, mas o afecto do susto - o trauma psíquico. De modo análogo, as nossas investigações revelaram que para muitos dos sintomas psíquicos havia causas desencadeadoras que só podem ser descritas como traumas psíquicos. Qualquer experiência que possa evocar afectos penosos - tais como o susto, a angústia, a vergonha ou a dor física - pode actuar como um trauma dessa natureza. ${ }^{5}$ (Freud, 1893/1996, p. 45)
\end{abstract}

Freud interpreta o fenómeno no contexto da sua teoria da histeria, a que dará um particular significado marcadamente sexual, dentro da sua compreensão do sistema económico-libidinal, cujas particularidades não são o que aqui nos interessa aprofundar. $\mathrm{O}$ que considero importante é a descoberta da relação entre dor e afecto - isto é, a experiência afectiva do penoso ${ }^{6}$-, em ligação a um acontecimento ou situação determinados no desencadeamento de um estado doentio. Há, pois, evidência de um tipo de dor, que é psíquica, no sentido em que não é originariamente física, e que não só é marca de mal-estar mas, mais

\footnotetext{
${ }^{5}$ Cito a tradução brasileira, modificada por mim.

${ }^{6}$ António Damásio (1999, pp. 71-76) reconheceu esta relação ao distinguir o que chama "dor-sensação" e "dorafecto", em cujo registo e regulação neuronais estão envolvidos mecanismos perceptivos e emotivos, que envolvem zonas neuronais diferentes. Enquanto que "a dor é a percepção de uma representação sensorial de uma disfunção localizada num tecido vivo", a dor-afecto consiste no eu saber que tenho uma dor. 
ferozmente, do sentir de uma aflição ou pena: um mal, não no sentido moral ou escatológico, mas anímico. A dor que, de repente, feriu o paciente assustando-o, ou provocando-lhe angústia ou vergonha, é capaz de repercutir em futuras vivências, repetindo como da primeira vez o mesmo efeito e, desse modo, alterando a sua existência quotidiana. É nessa medida que é traumática.

Winnicott, mais abrangente e realistamente, desconecta este acontecimento do possível contexto sexual, podendo ter lugar numa etapa pré-edipiana, e integra o conceito na sua teoria do amadurecimento. Considera que o trauma é tanto mais determinante quanto mais precocemente tenha acontecido, tendo origem numa falha ambiental grave. Esta pode compreender vários níveis (por exemplo, uma privação de algum tipo) e conduzir a um colapso precoce, que, na sua radicalidade, determina um corte no amadurecimento da criança e um recuo na sua relação com o real. ${ }^{7} \mathrm{Em}$ "O conceito de trauma em relação com o desenvolvimento individual no seio familiar”, numa definição paradigmática, diz Winnicott:

Um trauma é aquilo contra o que um indivíduo não possui defesa organizada, de maneira que um estado de confusão sobrevém, seguido talvez por uma reorganização de defesas, defesas de um tipo mais primitivo do que as que eram suficientemente boas antes da ocorrência do trauma. (Winnicott, 1989, p. 259)

Pode, então, ocorrer que a criança, sendo incapaz de resposta própria à medida da situação e a ela adequada - e sendo, pois, absolutamente carente (dependente) do cuidado ambiental, ${ }^{8}$ que lhe falha e a deixa desamparada -, perca de golpe a confiança nesse ambiente e naquilo que é o seu próprio poder ser. O trauma, neste sentido, poder-se-ia traduzir como $a$ dor da perda da confiabilidade, sem a qual a vida quotidiana se torna numa atroz experiência de insegurança e sofrimento, de desestruturação comportamental e do consequente sentimento de falta de espaço vital, presente em tantos casos de esquizofrenia. Neste contexto, a experiência inicial (o trauma) na sua instantaneidade não só não é esquecida, mesmo que não haja dela registro consciente, como, sobretudo, volta a ser efectiva uma e outra vez, ao longo

\footnotetext{
${ }^{7}$ Ao saltar do quadro da libido e do seu desenvolvimento bio-psicológico em Freud para o horizonte mais vasto e mais originário do que chama "processo maturacional", pode dizer-se que Winnicott, com a sua teoria do amadurecimento, alcança ainda maior acuidade que o iniciador da Psicanálise. Num texto programático da sua abordagem do pensamento de Winnicott, decisiva na Escola de São Paulo, Zeljko Loparic tem a audácia e a valentia de sublinhar esta radicalidade e de defender que ela implica, na história da psicanálise, uma "mudança de paradigma". Veja-se Loparic, 2011, p. 55: "Winnicott, tal como Freud, é um pensador radical. A sua obra exige leitores igualmente decididos, dispostos a levar em conta todos os aspectos importantes do seu novo paradigma e a romper, quando necessário, com usos estabelecidos".

${ }^{8}$ Veja-se Winnicott, 1989, p. 145: "O trauma é um fracasso relativo à dependência." Num excelente artigo, Leopoldo Fulgêncio (2004, pp. 255-270) resume, contrastando, as concepções freudiana e winnicottiana de "trauma".

Revista Natureza Humana, São Paulo, v.21, n.2, pp.112-129, 2019 
da vida, deixando quem a vive sempre à mercê do seu mesmo poder desgarrador, desorganizador, a que não consegue resistir. ${ }^{9}$ Estamos, neste caso, ante um fenómeno de dor e de sofrimento, fundamentalmente psíquico, mas envolvendo, geralmente, múltiplas manifestações somáticas e muitas vezes transcendendo o limiar do social, quer pela agressividade, quer pela falibilidade de uma atitude de responsabilidade e coerência ética. A hipotética simplicidade do acontecimento inicial traduz-se, pois, num estado complexo, em que a dor aguda se repete cronicamente em situações que podem até ser muito diferentes da que a provocou originalmente. A sua única defesa é a cisão psicótica, que, transformando a vida num esquema defensivo, guarda - em vez de dissolver - a ameaça inicial, só aparentemente esquecida, e converte o real numa permanente "área de perigo letal". ${ }^{10}$

Também aqui estamos, pois, perante um fenómeno que afecta a totalidade da existência. E que implica o irromper de um tempo, que fica retido e não passa.

\section{A dor como fenómeno cultural}

Os dois exemplos mencionados procedem de uma consideração genética do ser humano, que é tão pouco habitual encontrar na Filosofia, inclusive na fenomenológica. Estas falam, em geral, do ser humano adulto, normal e plenamente desenvolvido, capaz de consciência, poder de observação e auto-análise. Mas este sujeito filosófico não é nunca senão o herdeiro daquela criança e daquele bebé, que pouco a pouco, no melhor dos casos, foram aprendendo a sofrer e a resistir ao sofrimento. Os avanços da psicologia do desenvolvimento e, sobretudo, da psicoterapia constituem, por isso, um enorme favor para a compreensão do que é o ser humano, de como se forma aquilo que a filosofia estuda como "já formado". Porque ter em conta esse processo obriga a reformular a maneira de encarar a própria humanidade dos humanos, na sua singularidade individual e colectiva.

$\mathrm{Na}$ verdade, a aprendizagem do cuidado de si e dos outros, e o exercício de vida que permite a formação de uma estrutura de resiliência, têm repercussão não só nos comportamentos individuais, mas também nas formas de vida e cultura, podendo ser

\footnotetext{
${ }^{9}$ Sobre a questão da confiabilidade, veja-se Dias, 2011, p. 19: "Na psicose, [...] o amadurecimento foi paralisado num certo momento dos estágios iniciais, em função das falhas ambientais traumáticas. [...] A 'loucura original' foi o fragmento de segundo em que, quando bebé, ele perdeu momentaneamente o ser em função de uma reacção à falha ambiental. Sofreu uma agonia impensável e, imediatamente após, houve uma reorganização de defesas". 10 "A vida é vivida como uma permanente cilada do imprevisível da qual é preciso, sem cessar, se precaver. Atrás de todas as defesas, há uma ameaça de confusão, de um colapso de falsa integração" (Dias, 2011, p. 20). 
diferentes os instrumentos conceptuais e ideológicos com que em cada época se enfrenta a dor.

Ernst Jünger, em 1934, resumiu esta ideia de configuração epocal, dizendo: "Diz-me qual a tua relação com a dor e dir-te-ei quem és" (Jünger, 1934/1995, p. 13). Uma coisa é a coragem heroica, outra a disciplina ascética, por exemplo. $\mathrm{Na}$ era da técnica, que continua a ser a nossa, essa relação configuradora é, para Jünger, aquilo a que, justamente, chamou "objectivização":

A valoração da dor não é a mesma em todas as épocas. Há, evidentemente, atitudes que capacitam o ser humano para se distanciar muito das esferas em que a dor manda como senhor absoluto. Tal distanciamento manifesta-se em que o ser humano é capaz de tratar o corpo - ou seja, o espaço que o torna partícipe da dor - como um objecto. Esse procedimento pressupõe decerto a existência de um posto de mando situado a uma altura, a partir da qual o corpo é considerado como um posto avançado, que o ser humano é capaz de lançar ao combate e sacrificar a distância. Todas as medidas que, então, se tomam destinam-se não a escapar à dor, mas a resistir-lhe. (Jünger, 1934/1995, p. 34)

Não podemos abstrair da estética e ética jüngerianas da "mobilização total”, que subjaz a esta descrição do modelo de resistência à dor, para que se é educado na civilização ocidental da primeira metade do século XX. Mas a consideração biopolítica contemporânea não me parece, porém, desmenti-la, apesar da diferente estética. Antes pelo contrário, reforça esse padrão de resistência, com a integração social da farmacologia, enquanto elemento essencial ao desenvolvimento programado da vida socio-económica. A dor física, que constituiria um ideal erradicar, é considerada como um fenómeno inerente à condição humana, sendo porém controlável, seja mediante a disciplina, seja mediante drogas do mais diferente tipo, numa sociedade tecno-cientificamente apetrechada.

Em ambos os casos, esse controlo realiza-se mediante uma operação: a conversão do sofrimento ligado à dor em objecto de conhecimento e de intervenção técnica. Essa dupla operação requer um locus sobre o qual exercer a acção: o corpo, seja no seu aspecto estritamente carnal, seja enquanto sistema neurológico. Só porque podemos converter o corpo e os seus lugares em objecto, em si mesmo destituído de valor, é possível distanciar-nos dele e agir sobre ele como se não fosse nosso, como se, na verdade, pudéssemos não ter (dele) sentimento. Para Jünger, é justamente a relação não sentimental e meramente objectivadora à dor que permite resistir-lhe, dominá-la e vencê-la. Ao contrário da Empfinsamkeit romântica, a positividade técnica actua como uma "operação cirúrgica, mediante a qual a vida é extirpada 
da zona da sentimentalidade", o que, embora "num primeiro momento, seja sentido (empfunden) como uma perda", permite vir a alcançar uma certa "impermeabilização contra o acosso da dor". ${ }^{11}$

Parece que esta consideração cultural já nada tem que ver com o fenómeno simples de que partimos: a dor física, tal como é vivida pela mais terna infância. Mas não é assim. Aquilo que a civilização técnica alcança no controle da dor física não é senão uma culminação possível do que o processo de amadurecimento humano habilita, sem impor: a identificação isoladora de funções corporais e mentais, a conversão em objecto tanto de umas como, talvez, das outras - a possibilidade, portanto, de não as tratar como próprias e, sim, como processos maquinais externos, susceptíveis de controlo por um eu, ou self, senhor de si e de tudo o que possui como seu. Alguém que em vez de ser, se tem. Por isso pode ter mão na dor. Tal como um Estado totalitário submete, policialmente ou mediante o controlo mediático, os seus súbditos. A dor, mediatizada como objecto, deixa de ser uma experiência, para passar a ser expulsada e vista por fora, como um fenómeno cognitivo observável e operável.

Desvirtuar o seu carácter avassalador é poder fazer-lhe frente, convertê-la em algo passageiro e sem importância. É também, decerto, poder criar instrumentos sociais e institucionais de assistência médica e terapêutica, o que é incontornável num contexto biopolítico e, de modo geral, civilizacional. Mas é ainda da dor propriamente dita que estamos a falar?

Há em Jünger, sem perder o cunho ontológico do fenómeno da dor, uma reorientação da experiência dolorosa para a sua cognição, mediante o que poderíamos (quase deleuzianamente) chamar uma esquizo-análise: a separação ascética dos seus componentes cognitivo e sensitivo, susceptível, por sua vez e por essa via, de ser dominada, instrumentalizada, tecnicamente controlada por quem a padece. Essa linha de análise levarnos-ia, contudo, numa direcção que não podemos aqui explorar mais profundamente.

\section{A dimensão cognitiva da dor}

\footnotetext{
11 Jünger, 1934/1995, pp. 58-59: “O cunho peculiar dos tempos em que nos encontramos... [é outorgado pela] ordem técnica em si, esse magno espelho em que se refecte com clareza máxima a objectivização crescente da nossa vida, que se encontra impermeabilizado de maneira especial contra o acosso da dor. A técnica é o nosso uniforme".
} 
Numa diferente abordagem fenomenológica, de raiz husserliana, Agustín Serrano de Haro procura aprofundar a questão que nos ocupa, mediante a aplicação estrita do esquema noético-noemático. Defendendo a fecundidade desta via fenomenológica, procura caracterizar a especificidade do fenómeno doloroso, nas suas variedades, partindo da sua máxima simplicidade "física". Paradoxalmente, Serrano de Haro oferece, como resultado cognitivo da sua pesquisa, a consideração da irredutibilidade do fenómeno doloroso a qualquer conceptualização, isto é, à definição de uma essência ou conteúdo propriamente cognitivos da dor.

São dois os aspectos que me parecem especialmente relevantes. O primeiro diz respeito à caracterização da dor como um "excedente" na afecção; o segundo, dele derivado, à distinção estabelecida entre o "doer-me", enquanto modalidade noética, e o "mal" assim percebido como pena, enquanto conteúdo noemático. Penso que, no seu conjunto, estes dois aspectos permitem desenhar uma modalidade de "objectivação" da dor, presente na própria abordagem fenomenológica deste tipo. Ela passa, necessariamente, pela introdução de dois elementos de análise que, no presente estudo, não foram tidos como centrais na minha descrição fenomenológica: por um lado, a localização da dor; por outro, a sua relação a um "eu" que sofre. A consideração da dor como afectando fundamentalmente a existência e não propriamente um sujeito, na sua condição psicossomática, permitiu-nos até agora não atender especialmente à concretude das manifestações somáticas do padecer álgico, nem à sua percepção psíquica, que o localiza sempre no "meu" corpo. Serrano de Haro, embora concedendo que "o alvo em que a dor corporal incide e acerta" é o sujeito, ${ }^{12}$ que a percebe como algo seu, destaca também o registo linguístico desta experiência sob a forma do dativo e nunca de um nominativo: não dizemos "eu doo", mas "dói-me" (Serrano de Haro, 2012, p. 136). Parte, portanto, da experiência localizada como afecção específica de uma parte do corpo e não, como foi o nosso caso, do fenómeno totalizante com que se inicia o reconhecimento da dor como tal e que mostramos anteceder a consciência da sua localização. A topografia da dor conduz à função da consciência e da reflexividade, supondo, portanto, a referência intencional noético-noemática a qualquer dos seus níveis, bem como à afirmação de uma "diversidade estrutural" entre as duas formas primordiais de dor - a saber, física e espiritual.

É só neste contexto que tem sentido a aguda descrição do conteúdo noemático da dor propriamente dita, enquanto afecção, como o "excedente" da percepção. Ao contrário de

${ }^{12}$ Serrano de Haro, 2012, p. 139: "qualquer dor que supere o limiar do mero desconforto físico incumbe ao eu, altera-o nos seus afazeres e projectos, perturba o seu presente e futuro imediatos, fazendo-o sofrer". 
outros tipos elementares de sensação penosa ou aflitiva, como a fome, a sede ou a falta de sono, de que já falava Buytendijk, Serrano de Haro considera que

na dor física não se vive a falta de algo, mas o que sobra da afecção; não se sofre pela ausência de um bem, [...] mas experimenta-se o sobrar da dor ela mesma. [...] Aquilo de que se sente falta, na dor, é a ausência da própria dor. $(2012, \text { p. } 130)^{13}$

Esta referência remete, por um lado, para a presença de algo na consciência, a que se sobrepõe a dor ela mesma, e para a noeticidade do acto reflexivo, que a capta no seu ser noematicamente mais do que o corpo silente saudável ou mesmo o bom ânimo da vivência do dia-a-dia. Mas, nesse mesmo acto, a dor remete directamente a quem a sente: o sujeito consciente, que, desse modo, é afectado de imediato, sente e reconhece a dor como sua, esteja localizada em alguma parte do seu corpo ou, como o autor espanhol também admite, que "a dor intensa assalte e se apodere do eu, e a crónica o acosse e, quiçá, assole" (Serrano de Haro, 2012, p. 139). Em qualquer caso, o dado cognitivo novo e característico deste fenómeno é $o$ penoso disso que me sobra e que eu converto em objecto da minha rejeição, agindo para expulsá-lo ou, se recuperamos a linha jüngeriana, o assumo para poder resistir-lhe.

Serrano de Haro parece considerar que, de algum modo, semelhante acepção do estado doloroso seria incompatível com o seu significado cognitivo mais próprio. Pois o que ela revela é sempre "um mal": se, pelo menos inicialmente, não é percebida como tal, não é DOR. Percebê-la implica sempre tomar consciência, mesmo se ainda prerreflexivamente, de que me faz mal algo. Este "algo" poderá ser percebido como externo ou interno, catalogado sentimentalmente como uma coisa ou como um sucesso metabólico, mas não pertence à dor, a não ser como sua causa. O sentido noemático da dor ela mesma seria, pois, apenas o seu plus: o "fazer-me mal" - ou seja, bem vistas as coisas, o meu sentir-la como um doer-me.

Independentemente da perspectiva da subjectividade, introduzida pelo autor espanhol, ${ }^{14}$ esta consideração do alcance cognitivo da dor - isto é, do que ela dá a conhecer - parece-me

${ }^{13}$ A este propósito, veja-se o comentário de Trilles, 2017, p. 213: "O sofrer próprio diz respeito à realidade físico-anímico-carnal que somos. De facto, o "dói-me" torna-a presente porque, no bem-estar, o que é próprio do corpo que sou é passar desapercebido, dilatando-se para o mundo, que é a sua outra cara. [...] O esquema corporal, ordenado pré-reflexivamente para levar a cabo as actuações pertinentes da vida quotidiana [...] alterase quando a dor impera. Nesse mesmo instante, o corpo silente mostra-se, toma voz e não se cala até que o seu/meu sofrimento acaba".

${ }^{14}$ Penso, no entanto, que a perspectiva da subjectividade confina a compreensão do fenómeno à esfera antropológica, e que só a sua integração na dinâmica ontológico-existencial, que lhe é inerente, mas anterior à configuração da subjectividade, permite sondar o seu sentido ontológico. 
importante para compreender, finalmente, o seu horizonte ontológico-existencial, que, num último esforço de análise, espero poder, pelo menos provisoriamente, aclarar.

\section{A dor como experiência ontológica}

Retomo o fio inicial destas considerações. Numa primeira abordagem, destaquei que a dor é um sentir (e não algo que se sente) e que se vive sempre in actu, de repente, como um golpe, cujo impacto pode, porém, ficar retido e alastrar em reverberações múltiples, nem sempre localizáveis, mas sempre de grande intensidade. Não é uma pequena afecção que nos dá a conhecer "a dor", mas sempre e só o seu apresentar-se estentóreo, absoluto, totalizante e isolador de tudo o que a envolve. Não se trata de uma questão de mais ou de menos, de gradação, embora esta possa dar-se em concreto. Mas só percebemos a dor, como tal, quando ela é uma intensidade que nos avassala, seja de que forma for. Se não, não chega a ser mais que uma incomodidade. E embora o senti-la se possa traduzir em alguma expressão (um "ai", ou uma tontura, ou a paragem áfona num discurso...), no seu aparecer perceptivo é sempre prévia a qualquer palavra que a diga, antecede qualquer verbalização ou conceito. É essa a sua força e seu poder. Neste nosso caminho, a dor é um acontecimento singular, lacerante, marcante, potencialmente traumático e desestruturante da nossa quotidianeidade. E, contudo, podemos aprender a resistir-lhe, pelo menos, e a compreender-nos melhor, na nossa vulnerabilidade, a partir dessa penosa experiência, tal como a tradição moral ocidental, herdeira das escolas gregas e da ascética cristã, nos ensinou e habituou a aceitar.

Num segundo momento, a análise fenomenológica pôs a descoberto dois vectores complementares importantes: (1) detectou e expôs o carácter noemático da dor como sendo a de um mero excesso, isto é, a inconsistência de um conteúdo cognitivo, que não consiste em algo conhecido no acto de conhecer, mas no repúdio do que, física ou psicologicamente, se fez presente; (2) a interpretação tácita disso que sobra - a dor - como um "mal", isto é, como algo que "faz mal", não na acepção de uma "coisa má”, mas no “doer”, em geral, como consciência do "fazer(-nos) mal".

Em síntese, o fenómeno da dor parece-me caracterizar-se como um acontecimento radical e uma experiência-limite. Acontecimento - porque é sempre como da primeira vez, mesmo que a dor ou mágoa que sinto já a tenha vivido outras vezes. Talvez até, por isso mesmo, o voltar a senti-la é ainda mais terrível, porque à dor que me fere se soma a lembrança do seu doer. Experiência-limite - porque nela vivo o encontro com o que excede o 
meu estar a ser e poder ser em calma, o bem-estar, o que me permite ser e levar adiante a minha vida quotidiana; porque põe à prova a existência, na sua forma em cada caso minha.

Martin Heidegger, embora tardiamente, soube ter em conta este acontecimento, de que não falara em Ser e tempo, nem sequer nas Contribuições para a Filosofia, propriamente ditas. Mas a experiência penosa dos anos da guerra, da história que a antecede e anuncia, e da miséria moral e socio-económica que se lhe segue, conduz ao assumir da dor (Schmerz) como tema do pensar, na transição do primeiro início (da civilização poente) para o outro início, talvez incipiente, ou talvez apenas ainda só a preparar. Em textos póstumos, publicados recentemente, a questão da dor aparece e reaparece, embora sem uma tessitura que permita desenvolvê-la plenamente. Há nesses textos ecos de Jünger, também de Rilke, mas há, sobretudo, uma ideia fundamental, com metamorfoses, que começa a tornar-se presente em 1941/42, no texto que leva por título Das Ereignis: “A proximidade do longínquo, no seu carácter de Ser, propicia-se na dor da experiência da apropriação propícia (Heidegger, 2009, p. 236).

Sem poder dedicar-me aqui às implicações contextuais e textuais desta referência, limitar-me-ei a sublinhar os nexos temáticos, que podem aclarar-se algo mais noutros excertos. Neste, parecem-me notáveis duas conexões: a dor como experiência e a dor como acontecimento. Fazer a experiência da dor é deixar que aconteça ou se propicie a apropriação, pela qual o Ser (Seyn) se deixa compreender, pela qual o longínquo vem à proximidade. Deste "ir à proximidade" falavam os Feldweg-Gespräche, como um andar nas imediações do Ser, um estar aberto à verdade. A dor inquieta (beunruhigt) como uma ferida (Wunde) (Heidegger, 1995, p. 230), isola (Heidegger, 2013, p. 805). Ela é a experiência da "essência da diferença" (Heidegger, 2009, p. 129), em que ecoa a possibilidade de um twist (Verwindung), de uma despedida (Abschied). Ela é a "pura forma de descarga [Austrag] da verdade do ser" (Heidegger, 2015, p. 16), "a fenda ou rasgão (Riss) que se encobre no são e salvo (im Heilen)" (Heidegger, 2015, p. 422), e que, ao acontecer como tal, irrompe na sua verdade, arrancandonos à indiferença, ao adormecimento da rotina.

“Temos dor, porque a dor nos tem. Tem-nos porque, acontecendo, dá início à apropriação propícia” (Heidegger, 2015, p. 26). A dor que toma posse de nós, dilacerando o nosso bem-estar, é, por isso, para o Heidegger dos anos da guerra e do imediato pós-guerra, com os dois filhos prisioneiros na Rússia, o que revela o ser do "aí", em que o ser devastado se deixa ver como tal. Não está aqui em causa a dor meramente física, ou meramente psíquica, ou o juízo revoltado ou compassivo perante um momento histórico. É o fenómeno da DOR, 
na sua imponência que anula o humano, para revelar nele todo o seu feito de destruição, mas também, num twist ontológico, o salto da desgraça à graça, ${ }^{15}$ num ir-à-proximidade pela saudade: “das An-denken ist er-eignet und zwar im Schmerz" (Heidegger, 2013, p. 790) - na dor é propiciada a saudade, o pensar que recorda, comemorando, e, portanto, trazendo a ser o que não é - na sua ligação ao sido.

$\mathrm{Na}$ experiência da dor, na sua máxima autenticidade, dá-se, pois, um acontecimento, pelo qual quer a condição humana, em cada caso própria de quem sofre, quer o seu limite obscuro se manifestam com a máxima intensidade. Essa experiência é, pois, dupla: antropológica e ontológica. A vulnerabilidade à dor - seja na doença, seja no sofrimento espiritual ou psicológico - manifesta-se e aprende-se. À força de padecer educa-se a sensibilidade e abre-se ao cuidado de si e do próximo. Mas a proximidade do limite, o tenaz desafio vivido pela existência em risco, adivinhado e vivido na própria carne e no desolamento da alma, denuncia a finitude do ser que somos e o seu estar exposto a não ser.

\section{Referências}

Borges-Duarte, I. (2017). Mesura e desmesura em Heidegger. O ponto de vista ético. Studia Heideggeriana, 6, 65-102.

Damásio, A. (1999). The feeling of what happens. Body, emotion and the making of conciousness. London: Vintage.

Dias, E. O. (2011). Sobre a confiabilidade e outros estudos. São Paulo: DWW editorial. García-Baró, M. (2012). El dolor no enseña siempre. Crítica, 981, 27-31.

Fulgencio, L. (2004). A noção de trauma em Freud e Winnicott. Natureza Humana 6(2), 255-270.

Freud, S. (1893). Acerca do mecanismo psíquico dos fenômenos histéricos. In J. Strachey (ed.), Estudos sobre a histeria (Edição Standard das Obras Completas de Sigmund Freud, vol 2, pp. 43 ss). Rio de Janeiro: Imago, 1996. [Na Standard Edition of the Complete Psychological Works of Sigmund Freud, Ed. J. Strachey et al. (v. 2, pp. 3-17), London: The Hogarth Press.]

Heidegger, M. (1995). Felweg-Gespräche. In Gesamtausgabe (Bd. 77, I. Schüssler, Hg.). Frankfurt: Klostermann.

Heidegger, M. (2009). Das Ereignis. In Gesamtausgabe (Bd.71, F.-W.von Herrmann, Hg.).

\footnotetext{
${ }^{15}$ Sobre a radicalidade ontológica desta Kehre ou torção ontológica, pela qual pode na desgraça propiciar-se a graça, do descuido emergir o cuidado, veja-se Borges-Duarte, 2017, pp. 79-81. 
Frankfurt: Klostermann.

Heidegger, M. (2013). Zum Ereignis-Denken. In Gesamtausgabe (Bd. 73.1, P. Trawny, Hg.). Frankfurt: Klostermann.

Heidegger, M. (2015). Anmerkungen I-V (Schwarze Hefte 1942-1948). In Gesamtausgabe (Bd. 97, P. Trawny, Hg.). Frankfurt: Klostermann.

Heidegger, M. (2017/2018). Über den Schmerz (D. Koch \& K. Neubauer, Hg.). Stuttgat: Heidegger-Gesellschaft.

Jünger, E. (1934). Sobre el dolor (A. Sánchez Pascoal, trad.). Barcelona: Tusquets. 1995. [Über den Schmerz [1934], In Sämtliche Werke (v. 7, pp. 143-191). Stuttgart: KlettCotta, 1980.]

Loparic, Z. (2006). De Freud a Winnicott: aspectos de uma mudança paradigmática. Winnicott e-prints, 1(1), 1-29.

Musset, A. (2013). La Nuit d'Octobre. [s/1]: Editions la Bibliothèque Digitale.

Serrano de Haro, A. (2012). Elementos para una ordenación fenomenológica de las experiencias aflictivas. Anuario Filosófico, 45(1), 121-144.

Trilles, K. (2017). Intencionalidad y dolor. In Borges-Duarte, Sylla \& Casanova (orgs.), Fenomenologia hoje VI. Intencionalidade e cuidado (pp. 203-215). Rio de Janeiro: Via Verita.

Winnicott, D. W. (1989). Psycho-Analytic Explorations. Londres: Karnac Books. 